\title{
Pela adoção da perspectiva da pertinência em pesquisas comunicacionais $^{1}$
}

\section{Carlos Alberto de Carvalho e Leandro Lage}

\section{Resumo}

Este artigo, de natureza ensaística, propõe a noção de pertinência como elemento balizador em pesquisas comunicacionais. 0 ponto de partida é que se, há pouco tempo, desafios como a definição do "objeto da comunicação" pareciam indicar os principais percalços para as pesquisas comunicacionais, hoje é a escolha dos melhores caminhos metodológicos a trilhar que permanece em aberto. Se à primeira vista, no entanto, um titubear metodológico pode parecer negativo, visto sob outro prisma, 0 da riqueza e diversidade das pesquisas comunicacionais, as questões de método aparecerão positivamente como 0 amadurecimento da área, inclusive quanto a quais são seus "objetos", afinal, múltiplos e exigindo variadas abordagens metodológicas. A noção de pertinência que aqui desenvolvemos deve ser entendida como parte do esforço metodológico de compreensão da comunicação e suas problemáticas, a partir de três dimensões interconectadas: teórica, empírica e analítica.

\section{Palavras-chave}

Pertinência. Comunicação. Pesquisa. Hermenêutica.

Carlos Alberto de Carvalho I caco5@uol.com.br Doutor em Comunicação pela Universidade Federal de Minas Gerais (UFMG). Professor do Programa de Pós-Graduação em Comunicação da UFMG.

Leandro Lage I leandrorlage@gmail.com Mestrando em Comunicação pela Universidade Federal de Minas Gerais (UFMG).

\section{Situando as questões}

Segundo o dicionário Houaiss, pertinência (2001, p. 2197) é "aquilo que concerne ao assunto; o que diz respeito a". Um bom ponto de partida, portanto, para as reflexões que aqui propomos, é pensar a pertinência como noção balizadora das pesquisas em Comunicação, isto é, como orientação para que as bases teóricas, empíricas e analíticas implicadas nas investigações mantenham coerência entre si e apontem para uma mesma dimensão de soluções possíveis para as questões propostas.

Também no Houaiss encontramos 0 adjetivo pertinente (2001, p. 2.197), que, entre seus significados, "é o que se refere (a alguma coisa); concernente, respeitante; que vem a propósito; respeitante à finalidade a que se destina; que tem relevância ou validez". Este último significado é particularmente importante para nossa discussão, à medida que a noção de relevância ou validez tem sido, não somente para o campo das pesquisas comunicacionais, como para todos os demais, questão de difícil delimitação. 
Há critérios inequívocos que possam, ao mesmo tempo, oferecer garantias de relevância e de validez para as investigações do campo da Comunicação? Estamos diante de dimensões quantitativamente justificáveis, por exemplo, segundo delimitações estatísticas? Estamos diante do desafio de construir argumentos que deem conta de análises qualitativas asseguradoras de relevância e validez? Ou estamos frente à necessidade de conjugar as dimensões quantitativas e qualitativas, de modo a não deixar margens de dúvida quanto à relevância e à validez da pesquisa proposta? Em sendo a última a resposta que melhor delinearia metodologicamente o campo da Comunicação, quais seriam os elementos pertinentes e de pertinência que não deixariam dúvidas quanto a se ter adotado 0 caminho correto?

Embora sejam questões que têm merecido os melhores esforços de pesquisadores já há quase um século, considerando-se aqui os anos 20 do século passado como o da instituição de um campo de pesquisas mais "genuinamente" comunicacional, as perguntas anteriores parecem, ao contrário, levar a boas respostas, ter criado determinados impasses. Em grande medida, como consequência da ansiedade em ser considerado um campo científico, os investimentos de pesquisas comunicacionais muitas vezes se viram na mesma armadilha de outros campos das Humanidades: encontrar instrumentos metodológicos e refinamento teórico que lhes garantisse, à maneira das Ciências Naturais, a mesma acuidade supostamente permitida por critérios de definição com fundamento estatístico, mas, sobretudo, com capacidade de explicação racional para além da presença dos pesquisadores, meros organizadores de dados que não afetam nem seriam afetados por suas paixões e visões de mundo. Enfim, uma entidade capaz de agir de forma neutra diante de percursos e resultados.

A quem tem um mínimo de contato com questões espinhosas da constituição das ciências, seus métodos e engajamentos, fica clara a referência às suas concepções positivistas, ainda que muitas vezes não admitidas enquanto tal. Pelo que outros já realizaram de balanços históricos dessa concepção, aqui nos limitamos a indicá-la. Dentre diversos autores, Boaventura de Souza Santos (1989) faz um apanhado lúcido dessas questões, assim como indica outras possibilidades para se "fazer ciência" que aqui nos inspiram, em especial uma visada hermenêutica.

Eis, resumidamente, um conjunto de indagações que se manterão como pano de fundo para as reflexões que aqui propomos, as quais, por sua vez, não oferecem respostas de caráter "definitivo", à maneira de um guia para boas práticas de pesquisas em comunicação. Primeiro, porque propomos a noção de pertinência como parte de um esforço de tentar evitar 
concepções teóricas e metodológicas que possam sugerir algo próximo de uma panaceia para as questões epistemológicas nas investigações comunicacionais. Segundo, porque pensar em termos de pertinência é assumir o risco diante daquilo que defendemos como acerto, isto é, que o campo comunicacional não pode estar sujeito a uma única diretriz metodológica ou a uma pretensão de unidade teórica.

Reconhecer a diversidade de métodos e teorias possíveis para explicar e compreender o campo comunicacional não significa a impossibilidade de unidade heurística. Esta, contudo, não poderá ser assegurada senão a partir de uma proposição de pesquisa com coerência interna. 0 que aqui nos anima é, assim, a ideia de que atribuir coerência seria alcançar a pertinência de métodos, teorias e resultados, desenvolvendo uma equação que deverá levar em conta as interconexões entre as dimensões teórica, empírica e analítica, bem como suas particularidades.

0 que advogamos é que os "objetos" de qualquer ciência não existem em "estado puro" na natureza ou na sociedade, mas são construtos que adquirem significado e podem ou não ser pertinentes à medida que são articulados em torno da tríade teoria-empiria-análise, processo que envolve a interação com o pesquisador aspecto que retomaremos mais adiante neste artigo. Trata-se, como argumenta Rosseti (2010), de romper com o empirismo ingênuo, com a ideia de que é possível alcançar o que seria a realidade empírica da comunicação. A articulação dos diferentes objetos empíricos da comunicação - e seu amplo universo de fenômenos, que vão das mídias jornalísticas ao cinema, da publicidade às modalidades de comunicação organizacional, entre outros - está sempre sujeita às perspectivas teóricas, a um modo de abordagem, bem como a uma dimensão institucional. ${ }^{2}$

0 que definirá um "objeto" como comunicacional, portanto, será sua construção enquanto tal, processo que não é nem aleatório nem relativista, mas articulado dentro daquilo que Luiz Eduardo Soares (1994), ao trabalhar com outro campo de investigações, a antropologia, indica como 0 "rigor da indisciplina", título, aliás, do livro no qual critica noções como o relativismo de que à primeira vista nossa proposição poderia ser acusada. Trabalhar dentro da perspectiva do "rigor da indisciplina" é reconhecer, como ponto de partida, que os métodos e as teorias de um campo de investigações nunca estão prontos à disposição do pesquisador, como um a priori que garantiria os bons resultados esperados ao final do trabalho de pesquisa. É também, não aceitar como cânones princípios teóricos e metodológicos que, embora de largo uso, não correspondam à complexidade da realidade que se busca compreender. É, sobretudo, reconhecer que, mesmo na suposta imutabilidade dos "objetos" das ciências naturais, não existe realidade estática. 
A "indisciplina" se torna, assim, uma espécie de iconoclastia frente a determinadas tradições que tentam se manter exclusivamente em função de sua suposta validez precisamente porque estariam inscritas na ordem das coisas inquestionáveis. E o rigor é exatamente o processo de permanente reinvenção teórica e metodológica capaz de, reconhecendo a riqueza, a complexidade, a dinâmica e a diversidade da realidade, propor os caminhos adequados para sua elucidação.

0 percurso doravante adotado começa pela apresentação, em separado, da articulação da mirada da pertinência com cada instância da tríade teoria-empiria-análise. A separação visa tão somente tratar com algum grau de detalhamento cada uma das dimensões, que devem ser entendidas sempre como interconectadas. Em seguida, buscar-se-á situar a ideia de pertinência como um elo entre as proposições de explicação, própria das ciências naturais, e compreensão, cara às humanidades, segundo a perspectiva hermenêutica de P. Ricoeur (1989) e seu diálogo com a epistemologia.

\section{Diversidade e historicidade das teorias}

Embora teorias e paradigmas não se confundam, especialmente porque as primeiras, mesmo às vezes situando-se em problemáticas e recortes distintos, podem portar uma mesma matriz paradigmática, no sentido de fundamentaremse em visões de mundo idênticas ou muito próximas, é sempre necessário, do ponto de vista metodológico, verificar a pertinência das teorias utilizadas, buscando desvendar os paradigmas que lhe são subjacentes. Ao promover este movimento, o pesquisador em comunicação estará municiado dos elementos que de fato lhe permitam identificar a historicidade das teorias com as quais lida.

Historicidade, nessa perspectiva, deixa de ser um mero marco cronológico para situar-se no campo mais abrangente das marcas paradigmáticas, de um "espírito do tempo" que, às vezes a despeito da atualidade de uma proposição em termos de calendário, é portadora de visões de mundo que há muito já não são mais capazes de compreender as novas dinâmicas da realidade sob escrutínio. Mas, o contrário também é válido: teorias "antigas" muitas vezes acrescentam frescor e novas perspectivas a análises sobre questões contemporâneas.

É comum, especialmente quando no marco de certos modismos teóricos, encontrarmos tentativas de explicações que não resistem a um exame mais acurado de suas origens paradigmáticas, revelando-se "ultrapassadas" relativamente aos "objetos" que visam esclarecer. Lidar com a historicidade das teorias também oferece a possibilidade de identificar paradigmas que agem no subterrâneo, tomando aqui a proposição de autores que sugerem serem tais paradigmas muitas vezes de difícil identificação, agindo como elementos ocultos que "driblam" o pesquisador (Cf. SANTOS, 1989; HAGUETTE, 1997). 
É preciso lembrar ainda que, no percurso

da construção do campo de pesquisas

comunicacionais, (re)descobertas de importantes aportes teóricos, alguns anteriores ao início do século XX, indicam que a historicidade, se não é mera questão cronológica, aponta para intercâmbios teóricos de matrizes situadas em distintas temporalidades. Em Comunicação, dois exemplos importantes de teorias cronologicamente "antigas" que ajudam a melhor compreender os intrincados processos de interação e de mediação implicados nos processos comunicacionais são as perspectivas do pragmatismo (POGREBINSCHI, 2005) e do interacionismo simbólico (HAGUETTE, 1997).

À noção de historicidade, importante para evitar a tentação dos modismos teóricos e também para suprimir supostas atualizações das teorias que, indicadas em suas condições de construções históricas, são às vezes forjadas como possibilidades explicativas quando não mais se prestam a tal, é necessário acrescentar a diversidade das teorias que podem informar o campo das pesquisas comunicacionais.

A diversidade de aportes teóricos tem a ver especialmente com duas condições do campo comunicacional: a interdisciplinaridade que marcou sua constituição e a quase infinita possibilidade de identificar "objetos" a partir das formas de comunicação em copresença e das modalidades mediadas por dispositivos técnicos interacionais. Neste último caso, às questões sociais são acrescidos os elementos tecnológicos, complicadores que por vezes embaçam a visão do pesquisador, rendido ao encantamento que aparatos crescentemente sofisticados são capazes de proporcionar, gerando confusões quanto às dinâmicas sociais e de linguagem efetivamente envolvidas em tais processos.

Essa diversidade de aportes teóricos traz algumas questões delicadas quando pensadas no marco da pertinência. Diante de tantos caminhos teóricos possíveis, qual o mais adequado? Um único aporte teórico é suficiente para lidar com determinados "objetos"? Se adotarmos mais de uma perspectiva teórica para explicar um mesmo "objeto", quais são as possibilidades de que elas se mostrem impertinentes?

0 problema é ainda agravado pela condição quase sempre dupla de inscrição dos "objetos" comunicacionais: na dimensão dos dispositivos interacionais e das relações sociais aí implicadas, sempre mediadas pela linguagem, que por si só constitui problemática espinhosa. Não nos propomos, é importante repetir, dar respostas metodológicas a estes desafios, mas indicamos a impossibilidade de ignorá-los no percurso das pesquisas em comunicação. Teorias e métodos necessariamente devem manter coerência entre si. E, em acréscimo, embora seja muito tentadora a possibilidade de um "ecumenismo teórico", na maioria das vezes o que se consegue é uma claudicante tentativa de fazer dialogar perspectivas teóricas que não se prestam a determinados diálogos segundo a necessária pertinência. 
Quaisquer que sejam as escolhas teóricas, no entanto, é fundamental evitar as tentações das grandes narrativas teóricas, que supostamente dariam conta, à maneira de metarrelatos, ou metateorias, de todas as dimensões de uma determinada realidade. Como Jean-François Lyotard (1998) alertou já há algum tempo, as pretensões das grandes teorias, sob a convicção de que explicariam a realidade em totalidade, não conseguiram outros resultados que não a compartimentação e/ou totalitarismos teóricos que, além de não explicarem aquilo que propunham, criaram riscos políticos de deixar à margem tudo que não se conformava às explicações forjadas.

Em Comunicação, ainda que talvez não identifiquemos tentativas de criar metateorias, certos investimentos que buscam dar conta de aspectos globalizantes dos "objetos", como simultaneamente abranger as dimensões históricas, tecnológicas e de linguagens implicadas em determinada realidade sob escrutínio, raramente conseguem ir além de descrições destes diversos aspectos, ainda que competentemente realizadas. Dificilmente são alcançáveis explicações teóricas que tenham capacidade heurística para descrever pertinentemente todos os elementos em suas supostas interconexões. Em situações assim, os "objetos" são considerados peças manipuláveis segundo os desígnios do pesquisador, submetidos a explicações teóricas que não raro lhes são absolutamente estranhas.
Ou então, risco não menos evidente, são repetidas fórmulas teóricas que condicionam os resultados antes de qualquer percurso analítico, transformado-o em mera formalidade.

0 aspecto mais importante é admitir que as teorias não podem pretender explicações definitivas da realidade e, acima de tudo, reconhecer a dinamicidade de toda e qualquer realidade sob investigação, que, por outro lado, deve servir como elemento para o reconhecimento da própria condição de historicidade das teorias. Dupla historicidade, assim sendo: das teorias e das realidades desafiadoras das teorias que buscam desvendá-las. Nas palavras do filósofo Karel Kosik (1986, p. 26, grifo do autor):

A teoria não é nem a verdade nem a eficácia de um modo não teórico de apropriação da realidade; ela representa a sua compreensão explicitamente reproduzida, a qual, de retorno, exerce a sua influência sobre a intensidade, a veracidade e análogas qualidades do modo de apropriação correspondente.

Se não nos propomos aqui a fazer um inventário das teorias da Comunicação, a citação de Kosik visa sintetizar nossa preocupação com a relação entre teoria e "objeto", ou realidade, que julgamos adequada, à medida, inclusive, que evita hierarquizações enganosas do tipo "a teoria como o que efetivamente dá conta da realidade, que lhe seria inferior", ou o inverso. Quanto aos inventários, já faz algum tempo que alguns 
autores têm se debruçado sobre as teorias da comunicação (EC0, 1976; WOLF, 1994, dentre outros), com leituras esclarecedoras sobre a riqueza dos seus aportes teóricos, assim como das limitações a que estão historicamente sujeitos. Sobre os paradigmas, não pretendemos ir além da indicação de que eles operam como espécies de visão de mundo que comandam as teorias, muitas vezes de maneira que não detectamos (SANTOS, 1989), e que estão também sujeitos aos fluxos históricos, como demonstraram, no plano mais geral das ciências, Kuhn (1997), e especificamente no campo da Comunicação, Quéré (1991).

\section{0 empírico em suas dimensões de corpora material e teórico}

A herança positivista mais persistente no campo das pesquisas Sociais e da Comunicação certamente está no complexo de inferioridade frente às Ciências Naturais, empíricas em essência, entendendo-se por isso especialmente a possibilidade de definição, segundo rigores estatísticos, de um corpus manipulável e verificável quanto aos resultados válidos ou não a partir do controle sob a forma de reprodução de experimentos em condições laboratoriais idênticas. De novo nos valendo de Santos (1989), esse entendimento sobre 0 fazer científico esteve na própria condição de possibilidade de estabelecimento das ciências, no que 0 autor chama de "primeira ruptura epistemológica", grosso modo, representada pela luta contra o senso comum e o pensamento religioso. No entanto, nas próprias ciências naturais este modelo já não é unânime e não suporta mais a complexificação que 0 desenvolvimento dos métodos e teorias experimentou nos últimos tempos.

A essa primeira ruptura, entende Santos (1989) que é necessária uma segunda ruptura epistemológica, ou uma "ruptura com a ruptura", de modo que o senso comum seja revalorizado em seus aspectos de instigação para a própria ciência e seus métodos, mas especialmente para que as ciências sociais e humanas passem agora a nortear os processos científicos. A mudança, nessa perspectiva, não pode ser apenas epistemológica. 0 autor propõe que a segunda ruptura deva ser promovida a partir de fundamentos hermenêuticos, favorecendo uma crítica dos próprios limites e potencialidades dos postulados epistemológicos. Acima de tudo está a necessidade de que o humano seja o foco privilegiado da nova concepção científica, a começar pela negação da ideia cristalizada de que o homem deve dominar a natureza, não por acaso, base primordial da definição do empírico que entre nós, da Comunicação, ainda reina na prática.

Se temos uma nova concepção de ciência em que o empírico passa a ser visto sob outro prisma, o da compreensão, parece-nos que no campo dos estudos comunicacionais é necessário verificar quais são as condições de pertinência na definição das empirias, a partir das quais, inclusive, são estabelecidos os corpora das pesquisas. Em primeiro lugar está a condição 
primordial de entendermos que as bases

estatísticas e as pretensões de amostragem, salvo em alguns casos de pesquisas de recepção, por exemplo, não são necessariamente as melhores definidoras da composição empírica das pesquisas comunicacionais. Pelo viés da pertinência, inclusive, há mesmo uma inversão da lógica: as bases quantitativas é que serão dadas pelo problema de pesquisa e pela ambição da investigação em termos da abrangência e do recorte, seja ele definido pela extensão cronológica - por exemplo, um determinado período de cobertura jornalística de uma temática específica - seja ele definido por outro critério.

Uma segunda condição é que, se a lógica do fazer científico está em processo de transformação, em que os "objetos" não deverão estar subjugados pela investigação, a empreitada tem que se reconhecer mais modesta, voltada para a interação entre pesquisador e "objeto", como adiante retomaremos. A desdogmatização do fazer científico passa, segundo Santos (1989), pelo reconhecimento de que não somos capazes de descrições totalizantes dos fenômenos que investigamos. Tal incapacidade é fato evidente no campo das pesquisas comunicacionais por razões diversas, que vão da diversidade das suas possibilidades de constituição de "objetos" ao fator essencial de que tratam de produtos e processos humanos, portanto, sujeitos a variações no fluxo histórico, portadores de uma dinâmica alucinante de transformações e, em uma de suas possibilidades, mediados por dispositivos interacionais de base sociotécnica.
Esse procedimento meticuloso certamente tem que reconhecer uma limitação das pretensões das pesquisas comunicacionais que, ao contrário de limitar-lhe o poder de explicação da realidade investigada, aumenta-0. Nesses casos, o olhar perspectivado confere maior acuidade. Outro ganho é 0 inevitável reconhecimento de que explicações científicas não se prestam a dar conta das antigas concepções de totalidade, mas apenas e tão somente de oferecer pistas provisórias sobre a realidade investigada. Realidade essa que, a propósito, em ambiente de reflexividade (GIDDENS, 1991), tem nas próprias proposições da ciência elementos para futuras transformações, também elas passíveis de investigação pelo viés das mudanças que as próprias pesquisas operam nos "objetos".

Nessa perspectiva, Santos (1989) nos indica que uma das condições essenciais da segunda ruptura epistemológica está na postura interpretativa em relação aos "objetos" a partir das interpenetrações entre resultados anteriormente obtidos em investigações científicas relativas a eles e as eventuais modificações que estes resultados propiciaram ao "objeto" agora novamente investigado. $0 u$, mesmo que a investigação seja sobre algum "objeto" ainda não escrutinado, é impossível negligenciar as interpenetrações das concepções científicas, culturais, ideológicas (no sentido de visões sociais de mundo) que marcam a realidade sob investigação.

Como se percebe, a constituição de uma empiria em pesquisas comunicacionais - formada tanto 
por produtos midiáticos quanto por processos de interação sem a mediação de dispositivos sociotécnicos - não se dá pela perspectiva do estatisticamente justificável à maneira dos procedimentos das ciências naturais, mas pela aplicação do princípio da pertinência que leva em conta a razoabilidade de não pretender 0 escrutínio de uma realidade pré-existente e em sua totalidade. Sempre sobrarão críticas quanto a algum aspecto não abordado na pesquisa, que, na visão de outro pesquisador, deveria ter integrado esta ou aquela variável. Quando não a superficialidade da análise - reduzida à descrição frente ao gigantismo da empreitada - seria a tônica dos avaliadores da pesquisa.

Há outra dimensão empírica nas investigações em Comunicação nem sempre considerada enquanto tal, mas que numa mirada da pertinência precisa ser reposicionada. Exceto em situações mais óbvias, como em pesquisas cujo "objeto" são as próprias apreensões teóricas no campo da Comunicação, à maneira de um mapeamento, acostumamo-nos a considerar o conjunto de textos teóricos a que recorremos um elemento à parte da empiria. Há uma lógica nessa atitude, à medida que tomamos as discussões teóricas como parte de um esforço de compreensão do "objeto" de pesquisa, mas não como componente do "objeto". Segundo essa perspectiva, o "objeto" não contém a teoria como parte da sua construção, mas deve ser explicado por ela.

Considerar o conjunto de textos teóricos como parte da empiria, como estamos sugerindo, é reafirmar o reconhecimento de que metodologias não são construídas apartadas das relações de pertinência com as teorias adotadas. Como propõe Braga (2011b), há pelo menos quatro níveis de utilização de pressupostos teóricos numa pesquisa: a) a escolha da perspectiva; b) a exploração dos conhecimentos já estabelecidos; c) os tensionamentos teóricos do objeto; d) por fim, revisões e complementos teóricos advindos dos resultados da pesquisa.

No quadro das relações de pertinência, cada um desses níveis de uso é afetado sobremaneira pela construção do corpus, assim como oferece as bases para sua escolha, recorte, descrição e análise. A escolha dos pressupostos teóricos, portanto, é parte do processo de constituição dos corpora, constituindo a dinâmica inicial da pesquisa (a definição do referencial de base, das teorias "estabelecidas"), do movimento analítico e interpretativo (o acionamento de alguns pressupostos e o descarte de outros), bem como do exercício conclusivo da pesquisa (que faz dialogar todos os níveis teóricos já mobilizados).

\section{A análise no percurso da pesquisa}

Incompatibilidade entre teorias, métodos e análise, fragilidade, inconsistência, brevidade e outros problemas são recorrentes como críticas aos exames dos "objetos" realizados em teses e dissertações da área da comunicação produzidas no Brasil. As causas parecem concentradas em três frentes. 0 sobrepujamento das discussões teóricas 
em relação às dimensões analíticas da pesquisa, a primeira, é certamente ainda o maior desafio que as pesquisas em comunicação têm de enfrentar. Não se trata, evidentemente, de uma simples inversão de prioridade, em que o problema estaria solucionado pelo "privilegiamento" da análise. A questão é de pertinência, à medida que 0 alongamento excessivo das discussões teóricas costuma refletir, paradoxalmente, o pouco amadurecimento das potencialidades analíticas do pesquisador.

Fatores como o tempo para a conclusão da pesquisa sem dúvida não podem ser descartados como uma das causas desse problema, diante da realidade de mestrados, doutorados e pesquisas financiadas que devem ser realizados em prazos controlados por programas de pós-graduação e agências de fomento. 0 par oposto do exagerado alongamento teórico é o tamanho excessivo do corpus. Segundo Braga (2011b, p. 22):

Um equívoco que às vezes ocorre é 0 de um levantamento muito abrangente e diversificado dos dados mal sistematizados - sobre os quais não se sabe, depois, como trabalhar interpretativamente ou como gerar ordem no caos informativo, para poder desenvolver inferências.

0 desequilíbrio parece estar centrado

mais propriamente na incapacidade de dimensionamento da pesquisa, por exemplo, com corpora empíricos que não podem ser adequadamente analisados no tempo disponível ou mesmo na própria extensão do trabalho, considerando os limites impostos às dissertações, teses e outras pesquisas.
Além dos problemas de dimensionamento, há também os desencontros entre teoria de base e a análise pretendida, gerando impertinências de variadas ordens. Uma delas leva, além de análises incapazes de refletir a riqueza do material que o pesquisador tem à disposição, a encaixes analíticos que forjam conexões inexistentes com as teorias. Por exemplo, obrigando o "objeto" a responder exatamente segundo as hipóteses formuladas no início da investigação, prevalecendo leituras lineares, mecânicas, quando não maniqueístas, incapazes de desenvolver a percepção das clivagens, porosidades e pontos obscuros dos materiais sob escrutínio que a empreitada de pesquisa deve levar em conta.

Outro fator importante está na própria definição do tipo de investigação, em muitas situações cometendo-se 0 engano de que, pela simples adoção, análises comparativas garantirão maior aprofundamento e qualidade da pesquisa. Quando se propõe uma análise comparativa, a primeira visada sobre a pertinência diz das possibilidades de se comparar materiais que guardem entre si aspectos em comum. Como comparar textos impressos e televisivos, que nas suas especificidades de dispositivos apresentam, dentre outras diferenças, problemas como as dimensões físicas do texto impresso (total ocupado na mancha impressa) e as dimensões temporais (o tempo destinado no conjunto da programação da TV), além, claro, de todas as nuances de linguagem que os distinguem? 
É bem possível estabelecer comparações entre as mesmas modalidades de suporte como, por exemplo, um telejornal matutino com um noturno, cujas propostas editoriais, públicos alcançados e linguagens adotadas são distintos. Há a possibilidade de se buscar exatamente tais diferenças, mas o risco será sempre enfrentar questionamentos do tipo "mas se isso já está na pressuposição da comparação, o que a pesquisa oferece como contribuição"? Claro, pode ser pertinente uma análise comparativa da cobertura de um mesmo tema por um jornal de matiz sensacionalista e um jornal de referência, em busca, por exemplo, da compreensão das dimensões éticas implicadas nas interações do jornalismo com os demais atores sociais. Os cuidados na busca da pertinência em tais circunstâncias são, contudo, redobrados. Não se deve nunca partir para uma empreitada analítica comparativa sob o argumento enganoso de que ela expandiria a compreensão do fenômeno investigado pelo automatismo da ampliação dos corpora e pela ilusão de que a comparação garante amplitude heurística.

Decidir por análises quantitativas ou qualitativas é 0 terceiro desafio que nos parece importante, e não pode simplesmente ser resolvido pelo caminho aparentemente mais óbvio: 0 da conciliação das duas, como se este gesto contivesse já a superação do desafio metodológico. Há possibilidades de excelentes pesquisas descritivas, de base exclusivamente quantitativa, quando, por exemplo, o que se pretende é a formação de um banco de dados, a detecção de recorrências, por meio da análise de conteúdo (LEAL; ANTUNES, 2011) ou em situações de levantamentos que antecedem abordagens qualitativas, preparando o terreno para pesquisas melhor qualificadas.

É preciso, assim, estar ciente tanto dos potenciais quanto das limitações do gesto metodológico adotado, não tentando fazer com que, por exemplo, uma análise de conteúdo ofereça interpretações que somente uma análise qualitativa poderia fornecer. Do mesmo modo, deve-se lembrar de que, ainda que seja somente para fins práticos, as quantificações e mensurações são inevitáveis para a construção de um corpus, seja ele composto por um registro cinematográfico (que requererá algum grau de decupagem), seja ele um conjunto de grupos focais (com uma quantidade $\mathrm{X}$ de participantes), ou mesmo um corpus de textos jornalísticos (dentro de um intervalo temporal ou segundo um número $\mathrm{Y}$ de edições).

Da parte das análises qualitativas, as impertinências mais comuns costumam estar associadas à ideia simplificadora de que elas são meras especulações em torno do "objeto", uma coleção de impressões subjetivistas. É já um lugar comum identificar em "pesquisas" sobre influências da televisão brasileira nos anos 1970 e 1980, especialmente sobre as telenovelas, que as próprias jamais eram assistidas, restando "análises" preconceituosas de quem, por trás da máscara da pesquisa, destilava toda ordem de ranços contra "um produto cultural de baixo 
nível, manipulador das massas ignorantes". A má fé pode ser a companheira fiel em supostas análises qualitativas, mas a ingenuidade quanto à facilidade da leitura dos "objetos" também não é boa companhia.

Como as pesquisas quantitativas enfrentaram fortes resistências, especialmente em um período ainda recente dos investimentos no campo dos estudos comunicacionais, acabou-se por criar a ilusão da pesquisa qualitativa como a panaceia salvadora das investigações em comunicação. É preciso cuidado com essa postura, inclusive reconhecendo que em pesquisas qualitativas é prudente que haja uma quantificação que permita melhor visualização da problemática em discussão. E o mais importante quando estamos diante das análises qualitativas: elas não significam meras impressões, mas o resultado de necessária habilidade e acuidade para perceber a complexidade do "objeto" sob investigação.

Em todos esses âmbitos e movimentos no quadro analítico das pesquisas em Comunicação, a ideia de pertinência entra como elemento organizador de procedimentos, podendo evitar a subsunção dos exames às discussões teóricas, os problemas de dimensionamento ou a má gestão dos tipos de análise.

\section{A propósito de uma conclusão, hermenêutica}

Propor a mirada da pertinência segundo a perspectiva hermenêutica significa menos oferecer um guia metodológico com categorias preexistentes - como o fez Thompson (1995), num movimento inevitavelmente redutor daquilo que a hermenêutica propõe - do que apresentar uma linha cuja função é coser os âmbitos teórico, empírico e analítico da pesquisa em comunicação, de modo que a tessitura da investigação resulte numa síntese produtiva da heterogeneidade de elementos que a compõem. E que 0 tecido final deixe transpassar a imagem ou forma mais clara do "objeto" em questão.

A adoção da perspectiva da pertinência significa, para nós, do ponto de vista de uma epistemologia do campo, fazer dialogar as proposições de explicação, oriundas das ciências da natureza, e de compreensão, próprias das ciências do homem. Uma hermenêutica compromissada com 0 gesto interpretativo diante do mundo, diria P. Ricoeur (1989), não partilha nem de um dualismo, nem de um monismo naquilo que diz respeito a esses dois processos. Tomando tal abordagem como base, entendemos que as investigações do campo da Comunicação deveriam se dispor a explicar os fenômenos e processos comunicacionais, mas também empreender o esforço de compreendêlos em sua complexidade, fechando o que 0 autor apresenta como "arco hermenêutico".

A compreensão de nossos "objetos" é, por um lado, o momento não metódico que antecede e põe limites à explicação, trazendo à cena a intersubjetividade. A compreensão também é, por outro lado, "inteiramente mediatizada 
pelo conjunto de procedimentos explicativos que ela precede e acompanha" (RICOEUR, 1989, p. 211, grifo do autor). A explicação, por sua vez, faz avançar a compreensão usando as pernas da objetividade. Enquanto a primeira mobiliza intersubjetividades, senso comum, pré-concepções, e mesmo sensações e afecções para a condução de nossas pesquisas, da escolha do "objeto" e eleição de teorias à observação, a segunda pesa todos esses elementos na balança da razoabilidade e da validez.

Parece-nos, então, que é somente adotando a ideia de pertinência como pedra de toque de nossas pesquisas, confrontando e modelando constantemente seus diferentes âmbitos e movimentos um ao outro, que teremos condições de compreender a dinâmica dos processos comunicativos e de explicá-los sem pretensões totalizantes e megalomaníacas. Nas palavras de Ricoeur (1989), que toma o paradigma da leitura para discutir a perspectiva hermenêutica como alternativa epistemológica às humanidades, "uma interpretação não deve ser apenas provável, mas mais provável que uma outra" (RICOEUR, 1989, p. 203). Isto é, se não podemos esperar desenvolver uma interpretação inconteste dos "objetos" que elegemos, deveríamos perseguir a que mais se encaixa - e que, portanto, é pertinente - às porosidades e regularidades dos processos comunicativos.

A virtuosidade hermenêutica está, desse modo, na integração das dimensões teóricas, empíricas e analíticas implicadas em cada gesto de pesquisa, proporcionando a dinâmica interacional na qual os objetos perdem suas aspas - até aqui utilizadas de forma a indicar certo titubeio sobre seu real significado precisamente porque reconhecidos como sujeitos em permanente diálogo com o pesquisador. E não meros alvos de manipulações grosseiras.

\section{Referências}

BRAGA, J. L. Constituição do Campo da Comunicação. Verso e Reverso, v. 25, p. 62-77, 2011a. , J. L. A prática da pesquisa em comunicação - abordagem metodológica como tomada de decisões. E-Compós, v. 14, p. 1-33, 2011 b.

ECO, U. Apocalípticos e integrados. São Paulo: Perspectiva, 1976.

FRANCA, V. R. V. Teorias, objeto de estudo, dimensão institucional. In: BARROS FILHO, C.; CASTRO, G. (Org.). Comunicação: práticas de consumo. São Paulo: Saraiva, 2007, v. 1, p. 103-112.

GIDDENS, A. As conseqüências da modernidade. São Paulo: Unesp, 1991.

HAGUETTE, T. M. F. Metodologias qualitativas na sociologia. Petrópolis, RJ: Vozes, 1997.

HOUAISS, A.; VILLAR, M. de S. Dicionário Houaiss da língua portuguesa. Rio de Janeiro: Objetiva, 2001.

KOSIK, K. Dialética do concreto. Rio de Janeiro: Paz e Terra, 1986.

\section{KUHN, T. A estrutura das revoluções}

científicas. São Paulo: Perspectiva, 1997.

LEAL, B. S; ANTUNES, E. 0 acontecimento como conteúdo: limites e implicações de uma metodologia. 
In: LEAL, B. S.; ANTUNES, E.; VAZ, P. B. (Org.).

Jornalismo e acontecimento: percursos

metodológicos. Florianópolis: Insular, 2011. v. 1, p.

17-36.

LÖWY, M. Ideologia e ciência social: elementos para uma análise marxista. São Paulo: Cortez, 1985.

LYOTARD, J-F. A condição pós-moderna. Rio de Janeiro: José Olympio,1998.

POGREBINSCHI, T. Pragmatismo: teoria social e política. Rio de Janeiro: Relume Dumará, 2005.

QUÉRÉ, L. D'un modele epistemologique da la communication a un modele praxeologique. Réseaux, Chachan, França, v. 9, n. 46-47, p. 69-90, 1991.

RICOEUR, P. Do texto a acção. Ensaios de hermenêutica II. Porto: Rés, 1989.

ROSSETI, R. A ruptura epistemológica com 0 empirismo ingênuo e inovação na pesquisa empírica em comunicação. In: BRAGA, J. L.; LOPES, M. I. V.; MARTINO, L. C. (Org.). Pesquisa empírica em Comunicação. São Paulo: Paulus, 2010, p. 27-49.

SANTOS, B de S. Introdução a uma ciência pósmoderna. Rio de Janeiro: Graal, 1989.

SOARES, L. E. O rigor da indisciplina: ensaios de Antropologia Interpretativa. Rio de Janeiro: Relume Dumará, 1994.

THOMPSON, J. B. Ideologia e cultura moderna: teoria social crítica na era dos meios de comunicação de massa. Petrópolis, RJ: Vozes, 1995.

WOLF, M. Teorias da comunicação. Lisboa: Editorial Presença, 1994. 
For the adoption of pertinence perspective in communicational researches

\section{Abstract}

This essay proposes the notion of pertinence as a guiding element in communication research. If not a long time ago challenges such as defining the "communication object" seemed to be the main difficulties facing communication research, today choosing the best methodological approaches remains an unresolved issue. Even if at a first glance methodological hesitation seems to be negative, looking from another point of view, that of the wealth and diversity of communication research, method issues will show to be positive regarding the full development of the area, including the questions related the definition of the "communication objects", which are multiple, requiring different methodological approaches. The notion of pertinence developed in this paper should be understood as part of the methodological effort to understand communication and its issues from three interconnected domains: theoretical, empirical and analytical.

\section{Keywords}

Pertinence. Communication.

Research. Hermeneutics.

\section{La adopción de la perspectiva de la pertinencia en las investigaciones comunicacionales}

\section{Resumen}

Este artículo, de naturaleza ensayística, propone la noción de pertinencia como un elemento orientador para las investigaciones en Comunicación. El punto de partida es el siguiente: si hace poco tiempo desafíos tales como la definición de "objeto de la comunicación" parecían indicar las principales dificultades para las investigaciones comunicacionales; hoy, la elección por los mejores caminos metodológicos a seguir permanece abierta. Sin embargo, si a primera vista, un titubear metodológico puede parecer negativo; visto desde otro prisma, el de la riqueza y diversidad de las investigaciones comunicacionales, los cuestionamientos sobre el método aparecerán positivamente indicando cierta madurez en el área, incluso en relación a cuáles son sus objetos - que son múltiples y exigen variados abordajes metodológicos. La noción de pertinencia que aquí desarrollamos debe ser entendida como parte del esfuerzo metodológico de comprensión de la Comunicación y sus problemáticas, a partir de tres dimensiones interconectadas: teórica, empírica y analítica.

\section{Palabras claves}

Pertinencia. Comunicación.

Investigación. Hermenéutica. 


\section{Expediente}

A revista E-Compós é a publicação científica em formato eletrônico da Associação Nacional dos Programas de Pós-Graduação em Comunicação (Compós). Lançada em 2004, tem como principal finalidade difundir a produção acadêmica de pesquisadores da área de Comunicação, inseridos em instituições do Brasil e do exterior.
E-COMPÓS I www.e-compos.org.br I E-ISSN 1808-2599

Revista da Associação Nacional dos Programas

de Pós-Graduação em Comunicação.

E-compós, Brasilia, v.15, n.3, set./dez. 2012.

A identificação das edições, a partir de 2008

passa a ser volume anual com três números.

\section{CONSELHO EDITORIAL}

Afonso Albuquerque, Universidade Federal Fluminense, Brasil Alberto Carlos Augusto Klein, Universidade Estadual de Londrina, Brasil Álvaro Larangeira, Universidade Tuiuti do Paraná, Brasil André Luiz Martins Lemos, Universidade Federal da Bahia, Brasil Ângela Freire Prysthon, Universidade Federal de Pernambuco, Brasil Angela Cristina Salgueiro Marques, Faculdade Cásper Líbero (São Paulo), Brasil Antonio Roberto Chiachiri Filho, Faculdade Cásper Líbero, Brasil Arthur Autran Franco de Sá Neto, Universidade Federal de São Carlos, Brasi Benjamim Picado, Universidade Federal Fluminense, Brasil César Geraldo Guimarães, Universidade Federal de Minas Gerais, Brasil Cristiane Freitas Gutfreind, Pontifícia Universidade Católica do Rio Grande do Sul, Brasil

Denilson Lopes, Universidade Federal do Rio de Janeiro, Brasil Eduardo Peñuela Cañizal, Universidade Paulista, Brasil Eduardo Vicente, Universidade de São Paulo, Brasil Eneus Trindade, Universidade de São Paulo, Brasil Erick Felinto de Oliveira, Universidade do Estado do Rio de Janeiro, Brasil Florence Dravet, Universidade Católica de Brasília, Brasil Gelson Santana, Universidade Anhembi/Morumbi, Brasil Gislene da Silva, Universidade Federal de Santa Catarina, Brasil Guillermo Orozco Gómez, Universidad de Guadalajara Gustavo Daudt Fischer, Universidade do Vale do Rio dos Sinos, Brasil Hector Ospina, Universidad de Manizales, Colômbia Herom Vargas, Universidade Municipal de São Caetano do Sul, Brasil Inês Vitorino, Universidade Federal do Ceará, Brasil Jay David Bolter, Georgia Institute of Technology Jeder Silveira Janotti Junior, Universidade Federal de Pernambuco, Brasil John DH Downing, University of Texas at Austin, Estados Unidos José Afonso da Silva Junior, Universidade Federal de Pernambuco, Brasil José Carlos Rodrigues, Pontifícia Universidade Católica do Rio de Janeiro, Brasil José Luiz Aidar Prado, Pontifícia Universidade Católica de São Paulo, Brasil Kelly Cristina de Souza Prudêncio, Universidade Federal do Paraná, Brasil.
Laan Mendes Barros, Universidade Metodista de São Paulo, Brasil Lance Strate, Fordham University, USA, Estados Unidos Lorraine Leu, University of Bristol, Grã-Bretanha Lucia Leão, Pontifícia Universidade Católica de São Paulo, Brasil Malena Segura Contrera, Universidade Paulista, Brasil

Márcio de Vasconcellos Serelle, Pontifícia Universidade Católica de Minas Gerais, Brasil

Maria Aparecida Baccega, Universidade de São Paulo e Escola Superior de Propaganda e Marketing, Brasil

Maria Ataide Malcher, Universidade Federal do Pará, Brasil

Maria das Graças Pinto Coelho, Universidade Federal do Rio Grande do Norte, Brasil Maria Immacolata Vassallo de Lopes, Universidade de São Paulo, Brasil Maria Luiza Martins de Mendonça, Universidade Federal de Goiás, Brasil Mauro de Souza Ventura, Universidade Estadual Paulista, Brasil Mauro Pereira Porto, Tulane University, Estados Unidos Mirna Feitoza Pereira, Universidade Federal do Amazonas, Brasil Nilda Aparecida Jacks, Universidade Federal do Rio Grande do Sul, Brasil Osvando J. de Morais, Universidade de Sorocaba, Brasil Potiguara Mendes Silveira Jr, Universidade Federal de Juiz de Fora, Brasil Renato Cordeiro Gomes, Pontifícia Universidade Católica do Rio de Janeiro, Brasil Robert K Logan, University of Toronto, Canadá

Ronaldo George Helal, Universidade do Estado do Rio de Janeiro, Brasil Rose Melo Rocha, Escola Superior de Propaganda e Marketing, Brasil Rossana Reguillo, Instituto de Estudos Superiores do Ocidente, Mexico Rousiley Celi Moreira Maia, Universidade Federal de Minas Gerais, Brasil Sebastião Guilherme Albano da Costa, Universidade Federal do Rio Grande do Norte, Brasil

Simone Maria Andrade Pereira de Sá, Universidade Federal Fluminense, Brasil Tiago Quiroga Fausto Neto, Universidade de Brasília, Brasil Suzete Venturelli, Universidade de Brasília, Brasil Valerio Fuenzalida Fernández, Puc-Chile, Chile

Veneza Mayora Ronsini, Universidade Federal de Santa Maria, Brasil Vera Regina Veiga França, Universidade Federal de Minas Gerais, Brasil

\section{COMISSÃO EDITORIAL}

Adriana Braga I Pontifícia Universidade Católica do Rio de Janeiro, Brasil Felipe Costa Trotta I Universidade Federal Fluminense, Brasil

\section{CONSULTORES AD HOC}

Ana Carolina Escosteguy, Pontifícia Universidade Católica do Rio Grande do Sul, Brasil Bruno Campanella, Universidade Federal Fluminense, Brasil

Edison Gastaldo, Universidade Federal Rural do Rio de Janeiro, Brasil Elizabeth Duarte, Universidade Federal de Santa Maria, Brasil Roseli Figaro, Universidade de São Paulo, Brasil

EDIÇÃO DE TEXTO E RESUMOS I Susane Barros

SECRETÁRIA EXECUTIVA I Juliana Depiné

EDITORAÇÃo ELETRÔNICA I Roka Estúdio

TRADUÇÃO I Sieni Campos e Markus Hediger
COMPÓS I www.compos.org.br

Associação Nacional dos Programas de Pós-Graduação em Comunicação

Presidente

Julio Pinto

Pontifícia Universidade Católica de Minas Gerais, Brasil juliopinto@pucminas.br

Vice-presidente

Itania Maria Mota Gomes

Universidade Federal da Bahia, Brasil

itania@ufba.br

Secretária-Geral

Inês Vitorino

Universidade Federal do Ceará, Brasil

inesvic@gmail.com 